\title{
For the record: British Columbia chapter has a Records Management Plan
}

\author{
Ana Rosa Blue and Elisheba Muturi
}

\section{Purpose}

Recognizing the value of records and information management, the Health Library Association of British Columbia (HLABC) wished to engage in best practices to control the creation and growth of its records. Such a plan could help support decision making, preserve corporate memory, ensure legislative compliance, and safeguard members' personal information [1]. Thus, the HLABC Records Management Plan was born.

\section{Setting}

As a professional association, HLABC needed records management policies to guide the Executive, safeguard important corporate memory, and dispose of unnecessary inactive records. This was all the more important since nonpaid limited-term executive members changed as their tenure ended.

\section{Method}

Ana Rosa Blue (President, 2008-2009) took up the challenge of organizing the HLABC's records. To do a competent job, she enrolled in a records management course [2], and the HLABC Records Management Plan (hereinafter referred to as the Plan) became her final class assignment. This proved invaluable as the project benefitted from the instructor's feedback and expertise. The next challenge was to roll out the Plan. A project timeline, built into the Plan, consultation with an ad hoc records management group, and approval by the HLABC Executive contributed to the roll-out.

\section{Results}

The following elements provide the framework for a sound records management plan [3]:
- Identifying the documentation needed for each function;

- determining the retention requirements based on business need and statutory compliance;

- keeping a record copy of each document in an official file;

- designating the position responsible for the official file;

- ensuring that HLABC officials understand their roles with respect to records management;

- regularly filing records according to the "file plan"; files break at year-end and new files are started;

- separating of "official" records from other materials (e.g., duplicates);

- cleaning up records once a year;

- Sending records of enduring (archival) value to storage (as HLABC does not have a permanent location, a staffed library was identified as the ideal storage site for HLABC's archives);

- maintaining inventory of records and their location by the Secretary.

The Plan's components are as follows:

- Inventory of documents

- Taking inventory is a vital step in identifying and analyzing the records created. It is also an essential tool in developing the "file plan" and determining the length of time that records should be retained, thus forming the records retention and disposal requirements.

- Privacy policy and procedures

- These guide the organization in complying with privacy legislation and principles [4], including accountability, limiting the collection and use of personal information to legitimate purposes, and providing access to this information.

- Timeline with action items

- This step is useful as part of the overall project management plan. It identifies the milestones and keeps the

A.R. Blue. Assistant Librarian, WorkSafeBC - Corporate Library Services, 6951 Westminster Highway, Richmond, BC V7C 1C6, Canada.

E. Muturi. ${ }^{1}$ Program Analyst, Drug Use Optimization, Pharmaceutical Services, British Columbia Ministry of Health, $303-960$ Quayside Drive, New Westminster, BC V3M 6G2, Canada.

${ }^{1}$ Corresponding author (e-mail: en_muturi@yahoo.ca). 
project on track in getting the records management plan up and running.

- Records retention and disposal plan

- This essential component underpins the critical ability of an organization to retain records of enduring value while disposing of inactive records no longer needed. By prescribing how long records should be retained, it ensures that records are weeded at the appropriate time.

- The "file plan"

- This is the classification structure that determines how the records are to be filed and assigns naming conventions and notations. The file plan can be subject based or linked to the functions and activities that generate the records [5]. It can be integrated with the records retention and disposal plan.

- Records management policy and procedures

- This ties all the above components together and outlines the responsibilities of HLABC officials in ensuring a successful records management program on an ongoing basis. The ultimate goal of the Plan is accomplished when this is in place.

The final Plan was presented to the Executive for their approval. Members of the Executive were briefed on it, and their unique role in implementing the Plan was impressed upon them.

\section{Discussion}

The Plan encompasses best practices that will ensure compliance with reporting and legal requirements.

The Plan will ensure that the HLABC "corporate" records are in order. The lessons learned are as follows:
- Executive members' questions and feedback, throughout the process, were important in keeping the project top of mind.

- Ongoing dialogue with Executive members kept them abreast of the project's progress and helped them appreciate their individual responsibilities in the final implementation of the Plan.

\section{References}

1. United States. Department of the Interior. 10 easy ways to improve records management [Internet]. 2009. [cited 12 July 2010]. Available from: http://www.doi.gov/ocio/records/tools/ questions.html.

2. Library and Information Technology [Internet]. Special topics: an introduction to records management. Vancouver: Langara College; c1994-2010 [cited 12 July 2010]. Available from: http://www.langara.bc.ca/science-technology/library-technology/ courses.html\#LIBR2295.

3. United States Environmental Protection Agency. Why records management? Ten business reasons [Internet]. c2007- [updated 5 July 2007; cited 12 July 2010]. Available from: http://www. epa.gov/records/what/quest1.htm.

4. Office of the Privacy Commission in Canada. Privacy Principles [Internet]. 2009. [cited 15 Dec 2010]. Available from: http://www.priv.gc.ca/leg_c/p_principle_e.cfm.

5. Robinson C. Records control and disposal using functional analysis. Sydney: Archives Authority of New South Wales. c2009. [cited 15 Dec 2010]. Available from: http://www. records.nsw.gov.au/recordkeeping/keyword-products/recordscontrol-and-disposal-using-functional. 